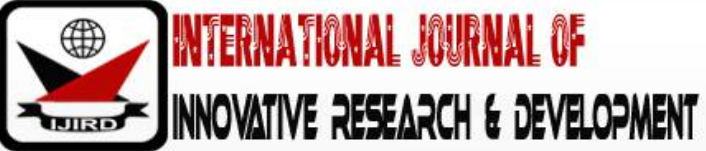

ISSN 2278 - 0211 (Online)

\section{Assessment of Quality Challenges of Practice-Based Research Reports: A Case Study-Bachelor of Technology in Graphic Design}

\author{
Dr. George Brako-Hiapa \\ Senior Lecturer, Department of Graphic Design Technology, \\ Takoradi Technical University, Ghana \\ Dr. B. J. Sebbeh \\ Senior Lecturer, Department of Graphic Design Technology, \\ Takoradi Technical University, Ghana
}

\begin{abstract}
The study concerned itself with the exploration of challenges and hidden errors affecting the quality of research reports written by Bachelor of Technology (B-TECH) students from the department of Graphic Design Technology, Faculty of Applies Arts, Takoradi Technical University, in Ghana. The study which is qualitative in nature and specifically an action research sought to identify, describe and analyse the most recurring type of challenges that impact on the quality of students' theses and proposes effective interventions in addressing the challenges. The study was conducted on twentyfive (25) BTECH research project reports emerging from a Practice-Based research which were purposeful sampled out from 2012/ 13 to 2017/ 18academic year collection. The findings of the study revealed essential errors and challenges associated with students' research reports that largely had impact on the quality. These include inconsistency in the order of arrangement of sections, typographical and grammatical errors, inconsistent use of terms and word processing style, ineffective use of sources and inappropriate use of signal phrase and verbs, incorrect documentation of sources (referencing). Similarly, the results of the study largely confirm students' inability to provide a comprehensive description and analysis of their new studies and the processes of production. The implication of the study is that, if the most recurring type of challenges or problems associated with students' write-ups are identified and better understood, the department of Graphic Design Technology in Takoradi Technical University would be better equipped with information and put down effective interventions that will help improve upon thesis/project writing arising from a practice-based research to meet high academic standards.
\end{abstract}

Keywords: Quality challenges, practice-based research, graphic design, research report

\section{Introduction}

Research is a major component of higher education and for that matter thesis and project writing has been a requirement for the diploma and higher degrees awarded from most institutions of higher learning including Polytechnics and Technical universities in Ghana.

In recent times, the dynamics of academic research conducted in the visual arts has changed and go beyond the traditional written essays where the results of most research may be fully described in text form without the inclusion of a creative work. The contemporary practices in the visual arts combine skill-based instruction methods of conceptual exploration and artistic research. One of the crucial points noted is that all art experiences combine meaning with making and students are expected to solve problems through engagement with materials and research methods.

Most often the research of some students results mainly in a practical outcome (artefact). This means that such students create works of art after going through rigorous creative processes with more emphasis on the practice and the outcome.

This dimension has given rise to studio practice-based research among contemporary visual artists because as Cora (2010) put it, practice-based research is rich with possibilities for contributing to the body of knowledge concerning creative processes, primarily because it has at its core the "making" disciplines.

According to Candy (2006) practice-based research is an original investigation undertaken in order to gain new knowledge partly by means of practice and the outcomes of that practice. Brabazon (2010) also emphasises that, practicebased research is a research methodology in which an artefact is created by the researcher. This assertion is supported by Burgin (2006) who states that practice-based research is designed for those who wish to create. It is envisaged that some students are interested in ideas, and as such read enthusiastically and turn concepts encountered in reading into practical projects. The research of such type of students typically has mainly, a practical outcome. 
The views expressed here infer that creative output is an integral part of the practice-based research process. The creative artefact is therefore the basis of the contribution to knowledge and has the potential to remain powerful (Cora, 2010). Ultimately the artistic knowledge of the creative artefact is embodied in the product or artefact itself and has to be acquired through sensory and emotional perception. Students therefore engage themselves more to produce outstanding works of art. However, for the purpose of academic research, there is always the need for the artefact to be accompanied by a written documentation of the research process, and in-depth description of the process of creation, as well as some form of textual analysis or explanation to support and enhance understanding of the artefact. More often than not students whose research are typically of practical outcome put more emphasis on the artefact with less importance given to thesis that accompany the individual projects. It should be emphasized that the outcome of the project and the thesis are of equal importance.

The Bachelor of Technology in Graphic Design is a top up programme designed for graduates of the Higher National Diploma (HND) in Commercial Arts (Graphic Design option) and holders of similar certificates and diplomas. Based on the in-depth knowledge and skills student acquire during the three-year HND Graphic Design programme, a four-semester top-up is organised to level up the required knowledge for industry and the award of the degree.

With reference to the accredited Bachelor of Technology in Graphic Design Curriculum-2016,the specific aims of the course are to create a centre of excellence by providing quality education based on competency training to

- Provide an opportunity for Higher National diplomagraphic Design Graduates and graduates with similar qualifications to acquire more knowledge and develop further professional skills, competences and attitudes relevant to the Graphic Design industry.

- Provide skills and knowledge-based programme which prepares students for employment in graphics and printing related industries such as Advertising and Packaging, Printing and Publishing, Photography and Multimedia, as well as making students self-employable in line with current national policy.

- Provide an opportunity for HND Graduates and people with similar qualifications to acquire advanced knowledge, skills and academic status in Graphic Design.

The B-Tech graphics programme offered at TTU, therefore, cover specialised studies in the following areas:

- Multimedia Design and Photography,

- Advertising and Packaging,

- Animation and Illustration,

- Prepress and Printing Technology

One essential point is that the emphasis in these specialized disciplines is on the creative process and the works that are generated from that process. It is more evident in such studies that contribution to knowledge may be demonstrated through creative outcomes in the form of communication designs, models, digital media, video documentaries, and performances but a full understanding of such works can also be obtained with direct reference to an exploratory and explanatory written thesis concerning the reflections upon the process undertaken.

The Department of Graphic Design Technology of the Takoradi Technical University combines skill-based instruction ranging from drawing to application of new technology with studio-based methods of conceptual exploration and artistic research. That is,studies in graphic design at the B-Tech level involves exploration of fundamental solutions to such problems based on creative thinking. The courses offer students the opportunity to develop creative concepts and critical thinking skills for Graphic design, to enable them establish unique bodies of ideas for work. Almost all of the study activities in Graphic design combine meaning with making, and students therefore, put their artistic skills and vision through engagement with materials and research methods in their creative studio practices.

Research methods is a mandatory course offered and for the partial fulfilment of the requirements for the award of the Bachelor of Technology Degree in Graphic Design. Therefore, final year students embark on a research project. They choose their own research project topics and work steadily for several months as they research, write, and manage a major independent project through studio practices.

In consonance with the nature of the course, it is obvious that majority of completed B-Tech Graphics students have undertaken practiced based research for which a set of objects that had been designed and constructed, formed part of their submission for the award of a degree. This implies that the final examination in thesis/ project writing for such students were based upon both the results of the practice (the creative work) and the exploratory and explanatory writeup of the research process undertaken. This infers that the candidate is subjected to scrutiny or assessment not only by the research results (the art work) but also the road he or she took to the goal, and the basis for presenting what he or she submits. With this, the candidate would be expected to satisfy the examiner in all of the ways that demonstrates that he/ she is well conversant with the general field of knowledge in which the subject relates.

The essential point is that, in art studio practice-related research, the emphasis is not only on the goal which is the art work (end product) but equally important the road to the goal or how the art work was achieved (Candy, 2006). The thesis that is written therefore must emphasize the reflections upon the process undertaken which is the research component of the studio practice to meet high academic standards.

The primary focus of the research is to advance knowledge about the quality challenges of Bachelor of Technology thesis/ project reports emerging from practice-based research. This is based on the findings of a pilot study conducted on five (5) sampled B-Tech thesis/ project reports. The findings revealed some level of challenges recurring in the research reports that negatively affects the quality as academic and scholarly materials. The main objective of the study therefore, is to identify, describe and analyse the most recurring type of challenges that impact on the quality of students' write-ups or research reports and propose effective interventions in addressing the challenges. As a lecturer at the department of Graphic Design Technology, we have a vested interest in improving the quality of student research projects at the B-Tech 
top-up level. The students are not first timers or beginners in conducting academic research projects since they once experienced it at the completion of their HND. B-Tech students are therefore, expected to exhibit some amount of proficiency in writing explanatory write-ups of the research process undertaken that meet high academic standards.

It is hoped that, if the most recurring type of challenges or problems associated with students' write-ups are identified and better understood, the department of Graphic Design Technology in Takoradi Technical University would be better equipped with information and put down effective interventions that will help improve upon thesis/project writing arising from a practice-based research to meet high academic standards.

\section{Methodology}

The study is a document review and purely Qualitative which generated narrative or textual descriptions of the phenomena under study. Document review according to Bowen (2009) is a way of collecting data by reviewing existing documents that may be internal to a programme or organization. The materials for the study (documents) are therefore sampled Bachelor of Technology thesis/ project write-ups submitted to the Department of Graphic design and Technology, Takoradi Technical University.

The specific research design adopted is content analysis. Content analysis is a detailed and systematic examination of the contents of a particular body of material for the purpose of identifying patterns, themes or biases (Leedy, 2005). The design was therefore pertinent to the study because it helped in the description of the body of material for study and gave precise definitions and descriptions of the characteristics to look for. The study therefore relied on the content analysis in the identification of challenges that impact on the quality of students' write-ups, by scrutinising the compositional structure, content and word processing of the various chapters. The Purposive Sampling was employed in selecting 25 write-ups emanated from studio practice-based research from 2012/ 13 to 2017/ 18 academic year's collection. The method deemed appropriate because the study materials appeared in different forms. Five (5) write-ups were selected from each year of the five academic years respectively.

The corpus for analysis included all parts of the research report as enshrined in the Guidelines for writing and submitting thesis/ project report (2012) for the Department of Graphic Design Technology, Takoradi Technical University as represented in table 1.

\begin{tabular}{|c|c|}
\hline Parts & Description \\
\hline 1 & Front matter or the preliminary pages \\
\hline 2 & Chapter One- Introduction \\
\hline 3 & Chapter Two- Review of related literature \\
\hline 4 & Chapter Three- Methodology \\
\hline 5 & Chapter Four- Design Development Strategy \\
\hline 6 & Chapter Five- Summary, Conclusions and Recommendations \\
\hline 7 & Referencing \\
\hline
\end{tabular}

Table 1: The Main Parts of the Sampled Research Reports

The main issues under investigation included the compositional structure comprising the order of arrangement of the various sections and features, documentation of sources, methodology features covering description and analysis of research design, techniques for collecting data, equipment, tools and material analysis, and the description and analysis of the processes of production. Other variables were typographical and grammatical issues, use of terms, word processing style and referencing.

The 25 sampled write-ups were subjected to an in-depth review analysis one after the other and the data retrieved were coded to themes and these represent the qualitative phase which add depth to the study.

For good ethical practice, permission was sought from the Head of Department, Graphic Design Technology before conducting the study. The identity of the authors of the sampled write-ups were kept confidential and not disclosed. No academic data on the merit of the sampled write-ups were used in the study. Write-ups which did not emanate from studio practices were not included in the population. Similarly, a copy of the report was shared with the office of the head of department as suggested by Brabeck \& Brabeck (2009)

\section{Discussion of Findings}

The following section describe data deduced from all the 25 write-ups and precisely presents a comprehensive analysis and interpretation of the findings. Bowen (2009) elucidates thatanalysing documents incorporates coding content into themes. The data retrieved from the study are therefore categorized into themes and represented in a descriptive form to facilitate interpretation. The emerging themes from the findings in effect are discussed under the following;

- Order of arrangement and pagination

- Typographical, grammatical errors, and word processing style

- Ineffective use of sources

- Incorrect documentation of sources,

- Description and analysis of the study and the processes of production. 


\subsection{Order of Arrangement and Pagination}

The findings revealed that all the write-ups begin with a front matter with the main body structured into five chapters and ends with references.

Inconsistency in the order of arrangement of sections under the front matter and chapter one was identified. Fifteen (15) write-ups which represents majority were found to have interchanged the positions of the declaration, abstract, acknowledgement and table of contents in the order of arrangement in the front matter. In some case a page contains more than one section instead of writing each section on a different page. The most recurring was locating the abstract and acknowledgement, table of contents and list of figures, list of figures and list of tables on the same page respectively.

Under chapter one (Introduction) similar interchanging of positions in the order of arrangement was observed. The most frequent existed among objectives, research questions/ hypothesis, delimitation/ scope, limitations, and importance of the study. Livingston (2012) says that proper sequencing in writing achieve a smooth, unbroken flow of narrative. It is therefore believed that when subheadings in the research report are well organized and connected in a proper sequence it provides a consistent discussion to the reader.

Another challenge that was identified was pagination of the front matter. Conventionally, the numbering of the front matter pages appears in lowercase roman numerals. The title page, which is the first page is counted in the numbering but do not bear any page number. However, 12 write-ups had the title page bearing the page number " $\mathrm{i}$ ". All these developments cast a slur on the quality of the affected reports since they do not conform to the standardise format. It therefore suggests that some students do not follow the correct order as prescribed by the Guidelines for writing and submitting thesis/ project report (2012) by the Department of Graphic Design Technology. This could be attributed to the fact that the students might have attached more importance to the created artwork than the accompanying report.

\subsection{Typographical and Grammatical Errors, and in Consistency in Word Processing Style}

The study revealed multiples of typographical and grammatical errors and among other things inconsistencies in word processing style across all the sampled reports. Error according to Merriam-Webster is "something that is not correct or accurate."Wordnet (2007) thus, explain typographical error asa mistake made in the typing process.Nordquist (2018) on the other hand states that, grammatical error is also called a usage error and it is used in describing an inappropriate verb tense or misplaced modifier. Tetzner (2017) emphasises that an excellent research report should be free from errors to impress readers with knowledge and understanding as much as it informs and interests them. However, contrary to this assertion each of the reports reviewed had more than one recurring error which is typographical, grammatical or word processing style which in effect, affects reader comfort. The following multiple errors and inconsistencies found testify how it affected the quality and optimum readability of the research reports.

- Spelling errors, transcription and transposition errors

- The flip-flopping of words such as "than" and "then".

- Omission of "s" in writing "Table of Content" instead of "Table of Contents"

- "Acknowledgement" as heading with not less than two persons acknowledged instead of "Acknowledgements".

- Capitalizing improper nouns and vice versa.

- Listing of nouns and/ or concepts like 1,2,3, 4, 5...instead of writing sentences.

- Not ensuring that the first letter of a sentence is capitalized, and all sentences ending with a full stop.

- Not using a space before parenthesis. E.g. "French(2011)" instead of "French (2011)"

- Punctuation mistakes

- Not putting a period or comma after quotes. "Time flies too fast."

- Inconsistency in line spacing,

- Inconsistency in fonts size,

- Jamming of section titles (e.g., 2.1, 2.2, ...) and sub-section titles (e.g., 2.1.1, 2.1.2, ...). In some instance both titles are sentence-capitalized in bold type or appear in normal type.

- Inconsistency and improper use of headings and subheadings.

The extracts indicate that editing which is an essential element was avoided in majority of the reports. The presence of these errors and inconsistencies eventually affect the accuracy, clarity and conciseness of the report making reading and understanding ineffective.

It is a known fact that for a successful satisfying written research report, it is essential for one to carefully edit and spell check his work. Ryan (2013) alludes to the fact that editing is by far the most crucial stage of the writing process and it is the only way to ensure high quality and optimum readability. The editing involves correcting spelling and grammatical errors, checking for proper paragraph and sentence structure, consistent use of terms, and variety in word choice. It could be inferred that either it was ignorance on the part of the students, or they did not devote much attention to the writing or did not see the need to edit and assess the overall structure of the thesis. Perhaps their focus on the contribution to knowledge was much vested in their creative outcomes which the artefacts are forgetting that a full understanding of the design of the creative outcome and the reasoning behind it are described in words. It is believed that the degree to which students personally invest in editing their thoughts and writing, will eventually play a large role in developing reader comfort. Any faulty construction of a sentence resulting from error in grammar, punctuation, spelling and typing have to be carefully and correctly edited otherwise the meaning of the sentences may be misunderstood or misrepresented 


\subsection{Ineffective Use of Sources and Signal Phrases}

Academic writings allow students to use other people's ideas or words but it is always important to decide when to quote directly and when to paraphrase your research sources. Creswell(2007)contends that "another ethical issue is that researchers should not claim that the words and ideas they use from others are their own; credit needs to be given using quotation marks. Whenever you paraphrase another author, you need to give them credit." The study however recorded inappropriate use of quotations and paraphrase in the literature review in almost all the reports studied. In many instances it was observed that quotes were lifted out of context and were not rooted in the topic or a point being developed. Quotations were seen not to be thoughtfully and appropriately used to enhance the quality of the reports. This infers that students just quote and refuse to comment on the significance or relevance of quotations to support or buttress their argument or assertion in order to clarify issues.

Similarly, paraphrasing was ineffectively done to enhance the quality of research reports. It was observed that paraphrases did not portray discussion of ideas and facts from sources. This means the way paraphrasing was done do not reflect completely one's own version or re-wording of something that have been read. It therefore suggests that students did not read to understand people's ideas or information and completely write their own version of it. This is what Keene and Adams (2001) refer to as a form of plagiarism called "plagiary phrasing" where one attempt to create some odd combination of the original wording of the texts and his or her own.

The findings revealed that the use of inappropriate verbs to introduce source materials recurring was also identified to be one of the challenges. This situation did not make quotations or paraphrases more meaningful in most cases. Verbs create different meanings in different contexts but from observation, majority of the students could not choose appropriate verbs to indicate or communicate their position or approach when applying signal phrases to introduce source materials.

It was also observed that majority of the students were not able to interconnect effectively the sections of their research report to provide a consistent discussion to readers. Creswell (2012) submits that one way to establish interconnection in a research report is by using key concepts as linking devices. Creswell explains linking devices as words or phrases that tie together sections of a research report.

\subsection{Incorrect Documentation of Sources (Referencing)}

The use of other people's ideas or words in academic writings by students are allowed but it is always important, both morally and legally, to acknowledge the source of ideas and information used within the write-up. Plagiarism is the use of someone else's work without giving him credit for the information (Creswell, 2007).It is therefore essential and appropriate to indicate the sources of the citations in the references list at the end of the paper to enhance the credibility and quality of the research report. It becomes an ethical issue in research writing if credit is not given for authorships(APA, 2010). It emerged from the findings that, other people's ideas and information used within majority of the reports were not indicated. Those that were indicated were also found to be incorrectly documented. This observation was recurring in both in-text citations and the reference list. Keene and Adams (2001) contend that when one fails to acknowledge the source of words or ideas used, the person may be accused of plagiarism and infringing copyright.

The following occurrences portray the incorrect documentation that negatively affect the quality and effectiveness of the research reports studied.

- Combining different style of format for making in-text citation or parenthetical references.

- Identifying source material by full name, title of book and year of publication for making in-text citation or parenthetical references.

- Misuse of quoting marks

- Inconsistency in style of constructing reference list. (mix styles)

- Use of et al appearing in the reference list.

- References cited in-text not appearing in the reference list and others not cited in-text appearing in reference list.

It is important to note that referencing is very necessary and essential in the sense that it demonstrates that one has really undertaken research on the study and located relevant information. Ballenger (2012) emphasises that including references in academic writing is one of the most important ways to demonstrate knowledge and understanding of previous studies about the research problem. He further states that it is the intellectual packaging around which the study is presented to the reader. Correct referencing therefore enables the reader or assessor of the write-up to verify the information used or read further to expand their knowledge on the topic. Incorrect documentation will therefore not allow the reader or assessor to retrace and locate information used and discover further views or ideas discussed by the author. All these challenges in effect, negatively impact on the quality and effectiveness of the research report as a scholarly material.

\subsection{Description and Analysis of the Study and the Processes of Production}

It is more evident that the contribution to knowledge through Practice-based Research may be demonstrated through creative outcomes in the form of the actual work of art produced. Apparently, a full understanding can also be obtained with direct reference to an exploratory and explanatory written thesis concerning the reflections upon the process undertaken (Candy,2006). Providing a comprehensive description and analysis involving all the practical activities and experiences the researcher engages in producing the actual work of art is essential.

Regrettably, the findings show students inability to provide a comprehensive description and analysis of their new studies and the processes of production. This implies that the core section of the thesis which encompasses what has been done, and how it was achieved was not treated scholarly. The discussions on the design and execution of set of experiments or 
the development and making of the innovative art works were not marked by an orderly and logical presentation in a clear and consistent manner.

It is hoped that a well written documentation of the research process, and in-depth coherent description of the process of creation, when provided in a proper sequencing to achieve a smooth, unbroken flow of narrative will enable the reader to obtain a full understanding of the study.

The findings further show that limited critical appraisal or analysis were given for the reader to obtain a full understanding of the creative works. This infers that the form of textual analysis or explanation given to support and enhance understanding of artefacts were inadequate in most instances. It is a known fact that the artistic knowledge of a creative artefact is embodied in the product or artefact itself and has to be acquired through sensory and emotional perception. However, it is envisaged that for the purpose of academic research, there is always the need for the artefact to be accompanied by some form of textual analysis or explanation to give real communicative value to enhance understanding of the art work.

\section{Conclusion and Recommendations}

The essential point is that study activities in Graphic Design combine meaning with making and students therefore put their artistic skills and vision through engagement with materials and research methods in their creative studio practices. Creative outcomes from the research process that students submit for examination are accompanied by written thesis or write-ups.The study has however established that there are major challenges and hidden errors affecting the quality of such theses or research reports emanated from practice-based-research and written by B-Tech students from the department of Graphic design and technology. The study makes it clear that the numerous challenges include; inconsistency in the order of arrangement of sections, sub-sections and other variables. These inconsistencies affected the delivery or expressions in an orderly and logical presentation to show transitions between major topics in a clear and consistent manner.

Furthermore, multiples of typographical and grammatical errors and among other things inconsistencies in word processing style were observed to disrupt reading which accounts for the ineffectiveness of the research reports. Similarly, the ineffective use of sources involving inappropriate use of quotations and paraphrasing, incorrect documentation of sourcesi.e. referencing, and students' inability to provide a comprehensive description and analysis of their studies and the processes of production negatively affect the quality and effectiveness of the research reports. All these inefficiencies adversely affect optimal readability.

Students should therefore adhere to effective use of quotation, paraphrasing and correct referencing with the intention of producing a correct, consistent, accurate and complete report. Similarly, they should invest time in thorough editing involving a rigorous review of their research reports, to check for avoidance of grammatical errors, unnecessary and awkward expressions, the mechanical elements of language covered, the text flow, and among others to improve and ultimately ensure high quality and optimum readability for a successful satisfying written research report.

It is concluded that majority of students do not produce standard explanatory write-ups of the practice-based research process undertaken. Probably, they put more emphasis on the production of the artefact and invest more of their time in the making process with less importance given to thesis that accompany the individual projects. It should be emphasized that both the outcome of the project and the thesis which gives a substantial contextualisation of the creative work are of equal importance. It means in studio practice-based research, the prominence should not only be on the goal which is the end product (art work) but equally important the road to the goal or how the art work was achieved. Therefore, in writing the thesis that accompanies the art work it should emphasize the reflections upon the process undertaken by describing the details of the method used, design of the study and critical appraisal or analysis of the art work which is the research component of the studio practice to meet high academic standards. A submission of such standards could be defined as a contribution of scholarly analysis and mastery of existing appropriate knowledge, in a form that is accessible.

\section{References}

i. American Psychological Association. (2010). Publication manual of the American Psychological Association (6th ed.). Washington, DC:

ii. Bachelor of Technology in Graphic Design Curriculum. (2016) NAB Accredited. Department of Graphic Design Technology, Takoradi Technical University: Ghana.

iii. Ballenger, B. P. (2012). The curious researcher: A guide to writing research papers.7th ed. Boston, MA: Pearson.

iv. Bowen, G. A. (2009). "Document analysis as a qualitative research method", Qualitative Research

v. Journal, Vol. 9 Issue: 2, pp.27-40

vi. Brabeck, M. M., \& Brabeck, K. M. (2009). Feminist perspectives on research ethics. In D. M. Mertens \& P. E. Ginsburg (Eds.), The handbook of social research ethics (pp. 39-53). Thousand Oaks, CA: Sage.

vii. Brabazon,T. (2010) Mick Winter Practicing Media Research, Master of Arts, Creative Media January 2010

viii. Candy, L. (2006). Creativity \& Cognition Studios. University of Technology, Sydney http:/ / www.creativityandcognition.com. Retrieved 2018-05-18

ix. Creswell, John W. (2012). Educational research: Planning, conducting, and evaluating quantitative and qualitative research - 4th ed. Boston; Pearson Education, Inc.,

x. Creswell, John W. (2007). Educational research: Planning, conducting, and evaluating quantitative and qualitative research - 4th ed. Boston; Pearson Education, Inc.,

xi. Guidelines for writing and submitting thesis/ project report (2012). Unpublished. 
xii. Department of Graphic Design, Takoradi Technical University.

xiii. Leedy, P.D. \& Ormrod, J.E. (2005). Practical research: Planning and Design. New Jersey. Prentice Hall

xiv. Ryan,E. (2013). Writing with Ryan: The importance of editing. http://www.self-pub.net/ blog/the-impotance-ofediting (Retrieved 19-05-2018)

xv. Burgin, V. (2006) "Thoughts on 'research' degrees in visual arts departments" Journal of Media Practice, Vol. 7, No. 2, p. 103-104

xvi. Marshall, Cora. (2010). A Research Design for Studio-Based Research in Art. Teaching Artist Journal, v8 n2 p77-87

xvii. Merriam-Webster Unabridged. Definition of error for Students Nordquist, R.(2018). Grammatical Error Definition and Examples. Updated January 18 https:/ / www.thoughtco.com/ grammatical-error-usage-1690911. Retrieved 1905-2018

xviii. Livingston, A. S. (2012). How to write an effective research report. Princeton, New Jersey: ETS Keene, M. L.\& Adams, K.H. (2001). Easy Access: The reference handbook for writers. Boston; McGraw-Hill.

xix. Wordnet definition. Wordnet. Princeton University. http:// wordnetweb.princeton.edu/ per/ Retrieved 2018-05-12.

xx. Tetzner, R. (2017). Advice \& Discussions on Preparing \& Submitting Journal Articles for Publication. https:/ / www.proof-reading-service.com/ en/ .../ write-research-paper-journal-publication. Retrieved 2018-05-26 